\title{
Moisture Reduction of Honey in Dehumidification and Evaporation Processes
}

\author{
Anang Lastriyanto ${ }^{1 *}$, Sasongko Aji Wibowo ${ }^{1}$, Erwan ${ }^{2}$, Firman Jaya ${ }^{3}$, Jati Batoro ${ }^{4}$, \\ Dewi Masyithoh $^{5}$, J.S.A Lamerkabel ${ }^{6}$ \\ ${ }^{1}$ Department of Agricultural Engineering, Brawijaya University, Malang, Indonesia \\ ${ }^{2}$ Department of Animal Husbandry, University of Mataram, Mataram, Indonesia \\ ${ }^{3}$ Department of Animal Products Technology, Brawijaya University, Malang, Indonesia \\ ${ }^{4}$ Department Biological Sciences, Brawijaya University, Malang, Indonesia \\ ${ }^{5}$ Department of Animal Husbandry, Islamic University of Malang, Malang, Indonesia \\ ${ }^{6}$ Department of Agrotechnology of Pattimura University, Ambon, Indonesia, \\ *Corresponding author:asenthil123@gmail.com
}

\begin{abstract}
The high water content of honey can lead to fermentation and accelerate the deterioration of honey. One way to prevent fermentation in honey is to reduce the water content of honey. There are several ways to reduce the water content of honey, namely through a dehumidifier and evaporation. This study aimed to examine the relationship of reduced water content towards time in between dehumidifier and evaporation processes. The research method uses an exponential equation model to determine the value of the constant $(\mathrm{K})$. The constant value $(\mathrm{K})$ is used to predict the rate of reduction in moisture content between the dehumidifier and evaporation processes. The results showed that the water content value after the dehumidifier and evaporation process had met the International Standard (SI) with a moisture content value of less than $19 \%$. The initial moisture content of honey before processing was $21.335 \%$, then after going through the process, the moisture content of honey in the dehumidifier and evaporation processes were $16.397 \%$ and $14.625 \%$, respectively. The processing time required for decreasing the water content of honey in between dehumidification and evaporation processes also shows a very significantly difference; In the dehumidifier process, the process takes $720 \mathrm{~min}$. While in the evaporation process, it is $50 \mathrm{~min}$. The exponential equation to determine the constant value of $\mathrm{K}(1 / \mathrm{min}$.) for the dehumidifier is $\mathrm{y}=21.262 \mathrm{e}$ $0.00037 \mathrm{x}$ with the value of regression $\mathrm{R}^{2}=0.9943$. While the exponential equation formula to determine the constant value of $\mathrm{K}(1 / \mathrm{min}$.) in the evaporation process is $\mathrm{y}=21.961 \mathrm{e}-0.007 \mathrm{x}$ with the regression value represent $\mathrm{R}^{2}=0.9262$.
\end{abstract}

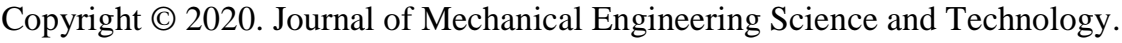

All rights reserved.

Keywords: Dehumidifier, evaporation, honey, moisture content

\section{Introduction}

Honey is considered as a natural food ingredient that has an essential role and have been utilized by human in everyday life since thousands of years ago. Honey is a natural liquid that generally has a sweet taste produced by honey bees (Apis sp.). It was a flower nectar that collected by bees, in which they will broke it down into simple sugars that are stored inside the honeycomb [15]. The honeys that are produced by honey bees are serves as food supply for their colony. The amounts of honey are abundant during the flowering season and it's stored inside nest cells as a food supply when the dry season comes. Bees produce honey with nectar materials, a liquid containing sugar secreted by plant nectar glands. Honey is one of the sweetener that is widely consumed by humans because of its nutritional content. Most 
of honey consists of sugar and enzyme complex that allows biochemical reactions to occur. These mechanisms of biochemical reactions will affect the quality of honey, resulted in the changes of the composition, taste, aroma, viscosity, and color.

Honey has high level of hygroscopic properties, means it is very easy to absorb water from the environment surrounded. Thus, the direct contact of air, will increasing honey's moisture content. The high-moisture content of honey can lead to fermentation and accelerate the deterioration of honey. According to the Indonesian National Standard (SNI), 8664 of 2018, the moisture content in honey acceptable by FAO (Food and Agriculture Organization) must be less than $22 \%$, while according to International Standards (SI) the permissible moisture content of honey is less than $19 \%$. There is a way to prevent fermentation in honey by reducing honey's moisture content until approximately less than $20 \%$.

A wide range of heating temperatures ranging from 30 to $140{ }^{\circ} \mathrm{C}$ for a few seconds to several hours has been practiced by honey producers worldwide to reduce the honey moisture content in honey until it is reaches a value below $20 \%$ in order to prolong their shelf life. On the other hand, heating with high temperatures could affects honey quality, such as the hydroxy methyl furfural (HMF) content and its enzymatic activity, which acts as parameters in determining the honey's quality. The closed system treatment will minimize the volatile fragrance loss during heating processes. The temperature used during heating process will have a significant effect on its moisture content. Honeys that are processed at $60{ }^{\circ} \mathrm{C}$ had higher $(\mathrm{RH})$ relative humidity $17.98 \%$ compared when they're heated at $70{ }^{\circ} \mathrm{C}$ and $80^{\circ} \mathrm{C}$, has the humidity value $17.06 \%$ and $16.40 \%$, respectively. In which thus temperature had no significant effect on honey moisture content that are packed in glass jars, plastic jars, and poly pack bags. Storage method and condition has substantial impact on honey's moisture content. Honey's moisture content will reduce to $16.41 \%$ when it stored in plastic bottles, while when honeys are stored in poly packaged bag, it is reduced, so it becomes $16.63 \%$. With the initial honey's moisture content value as big as $18.10 \%$. These results were observed after 12 months of storage time [2]. The experiments conducted by Zarei has resulted in lowering honey's moisture content to less than $20 \%$ after 30 min. of heating at $90{ }^{\circ} \mathrm{C}[14]$. They concluded that the increasing number in temperature is directly proportional to the honey's moisture content reduction rate. However, heating honey above $90{ }^{\circ} \mathrm{C}$ is strongly discouraged due to the cause of caramelization in sugars contains in honey [4].

There are some methods that are used to reduce honey's moisture content, such as utilizing a dehumidifier and through evaporation. Dehumidifier is a tool used to control the amount of water vapored in a room. This machine can be either portably or permanently installed in a room. Dehumidifier can reduce the relative humidity (RH) level at honey dryer room. The temperature used is usually around $45^{\circ} \mathrm{C}$, but the drying time is relatively very long. Other way to reduce honey's moisture content is using evaporation. Evaporation is a technique used to evaporate water in a tube by using a pressure below $1 \mathrm{~atm}$ or in a vacuum condition. Furthermore, water can evaporate at temperatures less than $100{ }^{\circ} \mathrm{C}$. Thus, makes the time used in evaporation method is relatively faster than the dehumidifier method. Gill has developed a small-scale honey dehydrator to reduce honey's water content from $25.2 \%$ to becomes $16.4 \%$. The experiments carried out to reduce the moisture of honey using air drying at room temperature [3]. Hot water is discharged in a water jacket around the honey pot to heat the honey. The heated honey pumped through a filter with 122 holes uniform in size, $0.5 \mathrm{~cm}$ diameter to form a honey stream through which the drying air passes to remove the honey's moisture content. The honey flow helps them to increasing the honey's surface 
to be exposed with the air. The maximum drying speed per square meter of honey exposed to drying air at $40{ }^{\circ} \mathrm{C}$ is $197.0 \mathrm{~g} /$ hour- $\mathrm{m}^{2}$ while the minimum result $\left(74.8 \mathrm{~g} / \mathrm{hour}-\mathrm{m}^{2}\right)$ corresponds to air drying at room temperature $8-17{ }^{\circ} \mathrm{C}$.

Yap et al., has developed a desiccant honey dehydrator that heat and dried the air to reducing honey's moisture content using desiccant bed silica gel. Re-circulation is used to extend the utilization period in using desiccant bed. Moisture reduction was carried out by dehumidified process at $35{ }^{\circ} \mathrm{C}$ and $45{ }^{\circ} \mathrm{C}$. Resulted in the reduction of honey's moisture content in the outdoor area. The maximum humidity evaporation rates using dehumidified air, the utilization of ambient air, and by reduce the humidity in an open container at $45{ }^{\circ} \mathrm{C}$ are $132 \mathrm{~g} /$ hour $-\mathrm{m}^{2}, 78.7 \mathrm{~g} /$ hour $-\mathrm{m}^{2}$, and $52 \mathrm{~g} /$ hour $^{2} \mathrm{~m}^{2}$ respectively [13]. The other experiment has been examined the evaporation process from raw honey and studied its dynamics process. The research was conducted for three years, using 79 samples of raw honey collected, 79 samples of dehydrated honey, and 69 samples of ripe honey. All of the honey sample was dehydrated using an air dehumidifier. The water content of honey decreased from $22.9 \%$ to $15.95 \%$ in 36 hours [6].

While Linkon et al., studied a honey reducer using falling film evaporator. In this multieffect evaporation system, raw honey preheated at $(40-45)^{\circ} \mathrm{C}$ and then filtered through an $80 \mu \mathrm{m}$ polypropylene microfilter. The honey is heated to $(60-65)^{\circ} \mathrm{C}$ in order to destroy the osmophilic yeast cells, held the temperature at $60{ }^{\circ} \mathrm{C}$ to evaporate the honey moisture content under vacuum condition, and then cooled down before passing the settling tank for further bottling step. The system can process around $300 \mathrm{~kg}$ of honey per day. Honey samples from three species Viz. A., Cerana, A., Mellifera, and A. Dorsata processed in the system. Has resulted in the reducing amount of water content in honey from $22.5 \%$ to $18.5 \%$ for A. Cerana honey, the reducing value has reached from $21.5 \%$ to $18.5 \%$ for A. Mellifera honey, and water content of A. Dorsata honey has been through reduction from $24.5 \%$ to $19.5 \%$ [5]. It has been observed that the higher the water content in honey, the higher the percentage of reduction needed at the same time. Besides, the more the reduction occurs in honey's moisture content, there is an increasing number in reducing the sugar value, unit weight, and etc.

Singh and Singh, use heated coils to exchange the heat after recirculated in hot water into honey. The honey is heated until $49^{\circ} \mathrm{C}$ and then pumped into a $1.2 \mathrm{~m} \times 2.4 \mathrm{~m}$ evaporation pan, then heated until $35^{\circ} \mathrm{C}$ using an air heater. In the form of a thin film with a thickness of 0.025-0.04 $\mathrm{m}$, the honey poured on the pan, the moisture content removed by blowing air onto the pan. In trials, around $75 \mathrm{~kg}$ of honeys were dried until its moisture content becomes $17 \%$ in 1 hour using two electric fans [11].

The reducing amount of honey's humidity stored in vats by heating the chamber until it reached $45^{\circ} \mathrm{C}$ using wood stove. The heat in the room will increases the temperature of the honey until $32{ }^{\circ} \mathrm{C}$. A portable air compressor made from $0.95 \mathrm{~cm}$ copper pipe, will produced bubbles to even the temperature distribution in honey. Warm air is supplied to each barrel to evaporate water from the honey. The fan moves the humid air above the barrel towards the wood stove to remove moisture from the room. The system runs for 19 hours, which resulted in reducing the moisture content from $18.5 \%$ to $17.7 \%$ [7]. Other study suggested a method used to minimize the pilled of honey's moisture content in vats. The barrel was placed in a room and heated until $(27-30){ }^{\circ} \mathrm{C}$. Dehumidifier will absorb the excess moisture from the air. A proper ventilation and ceiling fan for each room will beneficial for adequate air circulation to reduce the humidity [9]. 
Ramli et al., made an equipment consisted of a closed housing with an inlet port on the top side and an outlet port on the bottom edge. The honey will enter the inlet port and flows downward across a series of trays arranged in a zigzagged manner up to the outlet port. A metal screen is used on each tray to spread the honey evenly throughout the tray. There are a coil and an evaporator heater used to dry and warm the air circulated over the honey layer to remove moisture. This process claimed in reduced honey's water content from $20 \%$ to $18.5 \%$ with an airflow rate around $28 \mathrm{~m}^{3} / \mathrm{min}$. and a temperature used around $49{ }^{\circ} \mathrm{C} \mathrm{[10]}$.

Zarei et al., designed a small-scale honey moisture reduction system consisting of a rotating stainless-steel cone with $0.60 \mathrm{~m}$ in diameter and $0.65 \mathrm{~m}$ in high arranged in an isolated chamber. Portable blowers use to supply hot and filtered air. The moisture content of honey was reduced from 25.50 to $22.50 \%$. That process occurred in a single operation with the air temperature at $(65-67){ }^{\circ} \mathrm{C}$ was introduced into the system [15]. Platt and Ellis, have removed moisture from honey using dehumidifier with a thin contact film rotating disc at a speed of $10 \mathrm{rpm}$. Hot air is blown at $(45-75){ }^{\circ} \mathrm{C}$. The $1,468 \mathrm{~g}$ of honey with air velocity at $0.22 \mathrm{~m} / \mathrm{min}$. was reduced from $26.6 \%$ to $15.2 \%$ in 2 hours in the humidifier. This treatment was reduced honey's moisture content from 29.6 to $16.9 \%$ in 1 hour when honey flow was $15.3-16.0 \mathrm{~g} / \mathrm{min}$. with airflow at $50{ }^{\circ} \mathrm{C}$ and relative humidity value reached $27 \%$ [1], [8].

Determination of the value of constant $(\mathrm{K})$ using the exponential equation model can predict the rate of evaporation of water in the dehumidifier and evaporator. The constant speed of evaporation of water $(\mathrm{K})$ indicate that the machine uses the evaporation principle. Research on $\mathrm{K}$ by this far has focused on drying principle. The aim of this study is to examine the relationship between water content reduced along with the increasing time in between Dehumidifier and evaporation processes and comparing the most effective way in reducing honey's moisture content among both of them and determine the value of the constant $(\mathrm{K})$ using the exponential equation model to estimate the rate of moisture content evaporation during the process. So that in the future, this study can be used in invented the most appropriate and effectives way in degrading honey's moisture content to produce high quality honey.

\section{Materials and Methods}

\section{A. Materials and Equipments}

The tools used in this research were a set of the 1-liter capacity of water jet vacuum evaporator, a portable dehumidifier with dimensions of $35 \times 32 \times 27 \mathrm{~cm}$. other supporters. While the material used is pure honey obtained from the province of East Nusa Tenggara as much as 5 liters. The research was conducted at the Lastrindo Engineering Laboratory in Malang from March - April 2020.

\section{B. Methods}

The test is carried out by observing the rate of evaporation of water content in the honey using a dehumidifier and an evaporator. The test was carried out in 2 stages, the first stage with a dehumidifier and the second with an evaporator.

\section{Dehumidifier}

The first stage of the drying process uses a dehumidifier. The honey used comes from NTT forests. The $133.556 \mathrm{~g}$ honey sample was divided into three samples then poured into trays. The three samples were replicates 1,2 , and 3 . The sample weights in plates A, B, and 
C were $43.309 \mathrm{~g}, 44.846 \mathrm{~g}$ and $45.401 \mathrm{~g}$, respectively. The initial moisture content measurement was carried out before the three samples were entered into the dehumidifier. Measurement of water content was carried out two times; then, the average obtained to obtain the sample's initial water content value. After being averaged, the initial water content of honey was obtained. This initial water content is used as the Ho value for the three samples to be dried using a dehumidifier.

Furthermore, the observation was carried out by weighing each sample's weight every 1 hour (60 min.) once until the 12 hour (720 min.) - the RH value set to the lowest condition (CE) on the dehumidifier setting. Temperature is measured using a type $\mathrm{K}$ thermocouple connected to Omron Ecwl 5. Furthermore, any reduction in water content can be estimated by the mass balance equation (equation 1) concerning the law of conservation of mass, i.e., mass is not created and not destroyed.

Inflow $=$ Outflow + Accumulation

$$
\mathrm{H}=1-\left(\frac{\mathrm{Mo} \times \frac{100-\mathrm{Ho}}{100}}{\mathrm{Mn}}\right) \times 100
$$

Where:

$$
\begin{aligned}
& \mathrm{H}=\text { water content }(\%) \\
& \mathrm{Ho}=\text { initial moisture content }(\%) \\
& \mathrm{Mo}=\text { mass of starting material }(\mathrm{gram}) \\
& \mathrm{Mn}=\text { mass of material in the } \mathrm{n} \text {-hour (gram). }
\end{aligned}
$$

\section{Evaporation}

The second stage uses the evaporation method. The evaporator used in this research is the prototype scale evaporator. The tool is equipped with a vacuum pump jet and an evaporator tube. The evaporator tube used is a heat-resistant pyrex glass flask. The heating stove design was placed above the water bath. The honey ingredient used is honey obtained from NTT; the honey is the same type as the honey used for the dehumidifier sample. The $133.556 \mathrm{~g}$ honey sample used for the evaporation experiment was the same as the sample used for the dehumidifier process. The initial moisture content of honey is measured before the evaporation process. Then the honey is put into the evaporator and run. The vacuum pressure used is $7.8 \mathrm{kPa}$, and the temperature set on the control box is $45^{\circ} \mathrm{C}$. The stove flame will automatically decrease when the honey's temperature in the room exceeds $45^{\circ} \mathrm{C}$ so that the heat remains constant. Taking honey samples to measure the water content was carried out every $10 \mathrm{~min}$., then recording the water content reduction during the evaporation process. Sampling is complete when the measured honey water content has reached the equilibrium point.

3. Determine the Rate of Evaporation

How to determine the constant rate of evaporation of water in both the dehumidifier and evaporator is analogous to the method of determining the constant on drying, with the following steps:

1. Looking for massive data every specific time without interrupting the process.

2. Converting weight data to dry basis moisture data.

3. Based on the evaporation conditions at the relevant temperature, the equilibrium water content $\infty$ can be determined. 
4. Calculating the ratio of free water content (MR) of free water, namely the ratio of free water content at time $t$ to free water content at time 0 .

5. Plotting the data on the semi-log curve based on the exponential equation, then determining $\mathrm{K}$ based on the curve's slope.

In simple terms, the calculation steps above refer to Newton's Law of cooling solids with a decrease in Equation 2.

$$
\frac{\mathrm{dT}}{\mathrm{d} \theta}=-\mathrm{K}(\mathrm{T}-\mathrm{T} \infty)
$$

Where:

$\mathrm{T}=$ Temperature $\left({ }^{\circ} \mathrm{C}\right)$,

$\theta \quad=$ Time (min.),

$\mathrm{T} \infty$ = Equilibrium Temperature $\left({ }^{\circ} \mathrm{C}\right)$

From the above equation, an equation can be made to estimate the evaporation of water in drying honey. If the temperature $\mathrm{T}$ is expressed in terms of the water content of honey $\mathrm{H}$ $(\%)$, then Equation 2 can be made into Equation 3.

$\frac{\mathrm{dH}}{\mathrm{d} \theta}=-\mathrm{K}(\mathrm{H}-\mathrm{H} \infty)$

Where,

$\mathrm{H}=$ honey water content $(\%)$,

$\mathrm{H} \infty$ = equilibrium moisture content $(\%)$,

$\mathrm{K}=$ constant of water evaporation ( 1 / unit time).

Furthermore, Equation 3 is made into Equation 4.

$\frac{\mathrm{dH}}{\mathrm{H}-\mathrm{H} \infty}=-\mathrm{Kd} \theta$

Integration of Equation 4 with the initial $(\theta=0)$ and final $(\theta=\theta)$ boundary states into Equation 5.

$\frac{\mathrm{H}-\mathrm{H} \infty}{\mathrm{Ho}-\mathrm{H} \infty}=\exp [-\mathrm{K} \theta]$

Based on Equation 5, it can be seen the value of $\theta$ with Equation 6 as follows.

$\theta=\frac{1}{\mathrm{k}} \ln \frac{\mathrm{H}-\mathrm{H} \infty}{\mathrm{Ho}-\mathrm{H} \infty}$

Where,

$\frac{\mathrm{H}-\mathrm{H} \infty}{\mathrm{Ho}-\mathrm{H} \infty}=$ Moisture Ratio

Based on equations 5 and 6 , the constant value $(\mathrm{K})$ can be known to estimate the rate of evaporation of water during the process of decreasing the water content of honey.

\section{Results and Discussions}

Reducing the water content of honey is very important to maintain its quality because honeys are known for its hygroscopic properties, which means that it can absorb the water from the air so that honey will gain in the water content. As the result, honey will damage due to the fermentation process when it stored for a long time. The water content of honey 
permitted by Indonesian International Standard (SNI) to be able to marketed in the market place must be less than $22 \%$, while the percentage permitted by International Standard, it must be less than $19 \%$ in order to be allowed to circulate in the market. The results showed that reducing the water content of honey using two difference processes, dehumidifier and an evaporator to comparing its effectiveness in reducing the water content along with the increasing number of time in those different processes. The results depict with a constant value of $\mathrm{K}(1 / \mathrm{min}$.) using exponential equations to estimate the rate of reduction in water content during the two tools drying process.

\section{A. Reducing the Moisture Content of Honey Processed using Dehumidifier and Evaporation Method}

This research is focused in reducing the moisture content of honey using two different methods, dehumidifier process and evaporation process. Figure 1 showed the dehumidifier process of honey placed on the trays in order to reduce its moisture content. While Figure 2 showed evaporation process of honey inorder to reduce its moisture content. Figure 3. below are explaining the comparison of honey's moisture content reduced rate in between dehumidifier an evaporation method a long with the duration of processes.

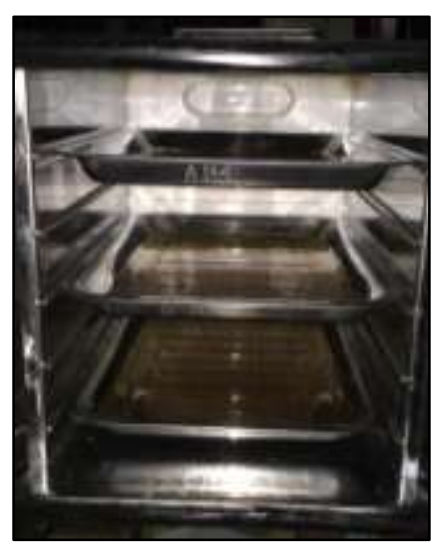

Figure 1. Dehumidifier use to decrease the amount of moisture content in honey sample

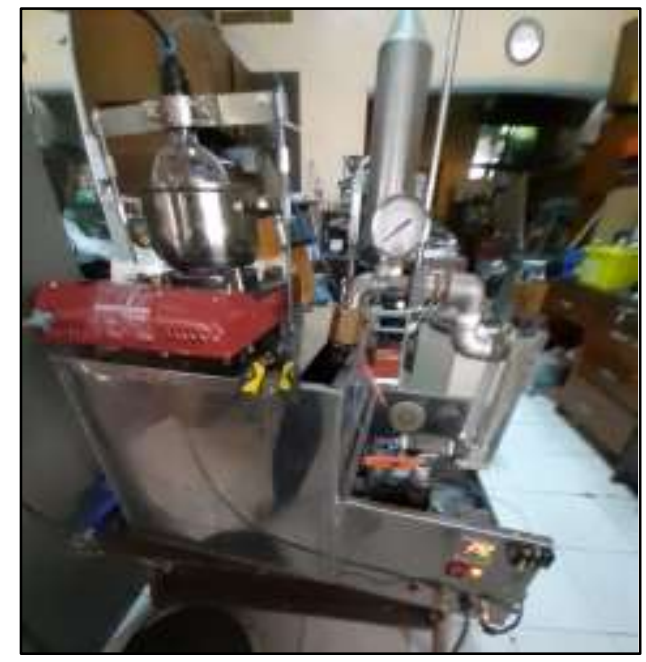

Fig. 2. The evaporator used to lower the moisture content in honey 


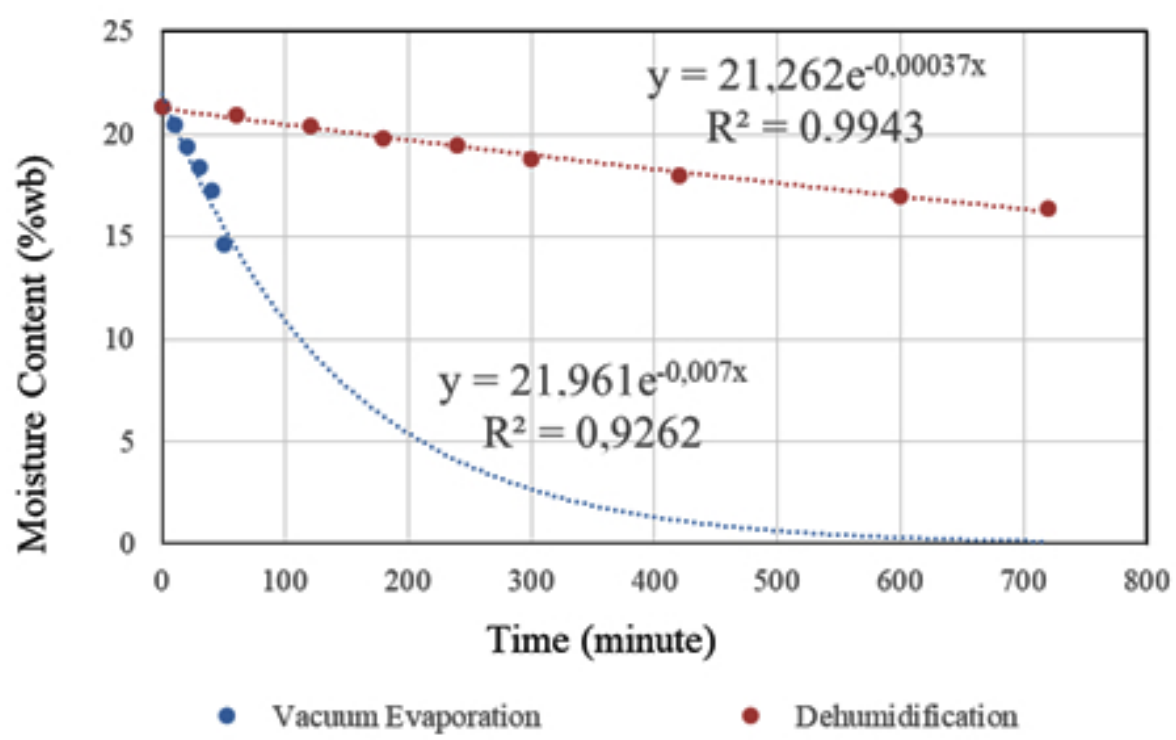

Fig. 3. The reduction rate of water content in honey after processed using dehumidifier (red line) and evaporation (blue line).

\section{B. Reducing the Moisture Content of Honey using Dehumidifier Method}

Based from Figure 3, the graph shows the average reduction rate of of honey's moisture content after processed using dehumidifier (red line) and evaporation (blue line). The initial water content was measured using a moisture analyzer, and the value is $21.335 \%$. Using Dehumidifier method, te average RH (Relative Humidity) value per hour was $38 \%$. The temperature sensor installed on the dehumidifier reads $45^{\circ} \mathrm{C}$. Furthermore, based on the mass equilibrium formula in equation 6 , the reduction of water content at the point up to 720 min. or 12 hours during drying is reaching the value $16.397 \%$. The Figure 2 also obtained the value of constant $(\mathrm{K})$, reached a value of $0.00037(1 / \mathrm{min}$.). This value is obtained from the exponential equation $\mathrm{y}=21.262 \mathrm{e}^{0.00037 \mathrm{x}}$, with the regression value shown is $\mathrm{R}^{2}=0.9943$. The constant $\mathrm{K}$ value is the rate of evaporation of water content per unit time (min.) during the dehumidifier process. It can be seen that the evaporation rate is meager in the dehumidifier. The constant $\mathrm{K}$ value shows the rate of evaporation of moisture per unit time (min.) during the dehumidifier process in honey.

\section{Reducing the Moisture Content of Honey using Evaporation Method}

In Figure 2 and Figure 3, evaporation was used to evaporate the water contained in the honey. The working principle of the evaporator machine used (Figure 2) is the decreasing number of pressure in the room below $1 \mathrm{~atm}$ will reduce the boiling point of water $\left(<100^{\circ} \mathrm{C}\right)$ following with the lowering number of pressure value in the room. The statement goes along with the results that are shown in Figure 3.

Based on Figure 3, the lowering value of moisture content in honey's after processed with the evaporator (Figure 2) shows that the value of honey initial moisture content before evaporation process $21.335 \%$. After evaporation conducted, honey's final moisture content value is decrease and reached $14.625 \%$, as long as $50 \mathrm{~min}$. in evaporation process conducted with the vacuum pressure value is $7.8 \mathrm{kPa}$. The measurement of water content level in honey was done every 10 mins using a moisture analyzer. Furthermore, the Figure 3 also obtained a constant value $\mathrm{K}$ of $0.007(1 / \mathrm{min}$.). That has been obtained from the equation $y=21.961 \mathrm{e}^{-0.007 x}$, with a regression value $\mathrm{R}^{2}=0.9262$. The constant $\mathrm{K}$ value 
indicate the rate of evaporation of water content level in honey per min. during the evaporation process. Comparing the results from the graph in Figure 3, the evaporation rate of honey's moisture content using dehumidifier process is lower compare in using evaporator method in evaporates the honey moisture content. Thus, using evaporator will give the time effectiveness in lowering honey's moisture content.

\section{Comparison of Dehumidifier and Evaporation Processes}

This study examines two methods used in reducing the moisture content in honey. The Honeys that are obtained from farmers usually has a high-water content. Thus, in order to be able to be circulated in the market place, moisture content in honey needs to be lowered below the Indonesian National Standard (SNI) or International Standard (SI) to avoid the fermentation process of honey. The study is focused in comparing the reducing value of honey moisture content using two different methods, dehumidifier process and evaporation process. The comparison of lowering honey moisture content using dehumidifier and evaporation are shown in Table 1.

Table 1. Comparison between the dehumidifier process and the evaporation process

\begin{tabular}{llrr}
\hline No & Observed process & Dehumidifier & Evaporation \\
\hline 1. & Initial water content $(\%)$ & 21.335 & 21.335 \\
2. & Final water content $(\%)$ & 16.397 & 14.625 \\
3. & Processing time (min.) & 720 & 50 \\
4. & Constant value (1/min.) & 0.00037 & 0.007 \\
5 & Regression $\left(\mathrm{R}^{2}\right)$ & 0.9943 & 0.9262 \\
\hline
\end{tabular}

From the Table 1, it can be seen that both of the final results lowering the number of honey moisture content using two different evaporation methos have met the International Standard value $<19 \%$, with the final value of honey moisture content after treated using dehumidifier and evaporation processes respectively represent $16.397 \%$ and $14.625 \%$.

The processing time required in the lowering the honey moisture content using two different methods, dehumidifier and evaporation shows a significant difference because there is a difference in pressure value. In the dehumidifier method, the process takes 720 min. with a non-vacum pressure value $101.3 \mathrm{kPa}$, while in the evaporation process takes 50 min. with a vacuum pressure value $7.8 \mathrm{kPa}$. The highlight of the study is that the vacuum conditions helps in lowering the evaporation time by reducing the pressure. Thus, when it's come in industrial scale application, the evaporation method is gives more effectiveness compare to the dehumidifier method because this method lowering the energy by lowering the pressure in order to reduce the moisture content in honey. The exponential equation were used to determine the constant value of $\mathrm{K}(1 / \mathrm{min}$.) in order to estimate the rate of evaporation of honey moisture content.

\section{Conclusions}

This study show that the moisture reduction rate of honey in evaporation based on moisture reduction constant around 15-20 times compare with demudification. Based on exponential equa, moisture reduction constant $\mathrm{K}$ in the dehumidifier process is $0.00037 /$ min. and $0.007 / \mathrm{min}$. with the regression $R^{2}=0.9943$ in humidification and $R^{2}=0.9262$ in evaporation. 


\section{Acknowledgement}

I want to express my gratitude to everyone who contributed and support me during my Research, my team and especially to the LPDP Institution. This work would never have been possible without the support and the fund from Educational Fund Management Institution (LPDP) during the research and final project.

\section{References}

[1] Ellis, M., "Lowering the moisture content in small lots of extracted honey". American bee journal, vol. 127(3), pp. 182-183, 1987.

[2] Ghazali, N. S. M., Yusof, Y. A., Ling, C. N., Othman, S. H., Manaf, Y. N. A., and Baroyi, S. A. H. M., "The Application of Clay Pot for Moisture Reduction of Geniotrigona thoracica Stingless Bee Honey", International Journal on Advanced Science, Engineering, Information and Technology, vol. 9, pp. 2028-2034, 2019.

[3] Gill, R. S., Hans, V. S., Singh, S., Singh, P. P., \& Dhaliwal, S. S. “A small scale honey dehydrator", Journal of food science and technology, vol. 52(10), pp. 6695-6702, 2015.

[4] Kurta, S. A., Khatsevich, O. M., Tsap, M. R., Ondrušová, D., Gromovy, T. M., and Boyko, N. V. "Biopolimeric Nano Structural Compositions Based on Caramelized Honey", Physics and Chemistry of Solid State, vol. 20(4), pp. 445-452, 2019.

[5] Linkon, M. R., Prodhan, U. K., Elahi, T., Talukder, J., Alim, M. A., and Hakim, M. A. "Comparative analysis of the physico-chemical and antioxidant properties of honey available in Tangail, Bangladesh”. Int J Res Eng Technol, vol. 4(3), pp. 89-92, 2015.

[6] Moise, G. "Research on quality analysis of an assortment of five types of honey in Romania". Scientific Papers Series Management, Economic Engineering in Agriculture and Rural Development, vol. 15(3), pp. 195-199, 2015.

[7] Nazzi, F., and Le Conte, Y. "Ecology of Varroa destructor, the major ectoparasite of the western honey bee, Apis mellifera". Annual Review of Entomology, vol. 61, pp. 417-432, 2016.

[8] Platt Jr, J. L., and Ellis, J. R., U.S. Patent No. 4,472,450. Washington, DC: U.S. Patent and Trademark Office, 1984.

[9] Pokhrel, V., DeLisi, N.A., Danka, R.G., Walker, T.W., "Effects of Truck Based UltraLow Volume Mosquito Adulticides on Honey Bees (Apis mellifera) in a suburban field setting", Plos One, vol. 13(3), pp. e0193535, 2018.

[10] Ramli, A. S., Basrawi, F., Idris, D. M. N. D., bin Yusof, M. H., Ibrahim, T. K., Mustafa, Z., and Sulaiman, S. A. "A new dewatering technique for stingless bees honey". In MATEC Web of Conferences, vol. 131, pp. 03014, 2017.

[11] Singh, I., \& Singh, S. "Honey moisture reduction and its quality", Journal of food science and technology, vol. 55(10), pp. 3861-3871, 2018.

[12] Suhag, Y., Nayik, G. A., and Nanda, V., "Effect of gum arabic concentration and inlet temperature during spray drying on physical and antioxidant properties of honey powder", Journal of Food Measurement and Characterization, vol. 10(2), pp. 350-356, 2016. 
[13] Yap, S. K., Chin, N. L., Yusof, Y. A., and Chong, K. Y. "Quality characteristics of dehydrated raw Kelulut honey", International Journal of Food Properties, vol. 22(1), pp. 556-571, 2019.

[14] Zarei, M., Fazlara, A., and Alijani, N., "Evaluation of the changes in physicochemical and antioxidant properties of honey during storage", Functional Foods in Health and Disease, vol. 9(9), pp. 593-605, 2019.

[15] [BSN] Badan Standardisasi Nasional, Madu SNI 8664: 2018 ICS 65.020. 99, 2018. 